\title{
Internal carotid artery velocities in patients with unilateral non-arteritic anterior ischemic optic neuropathy
}

\author{
Karen B. Reyes ${ }^{1,2}$, Andrew C. Hilado II', James F. Cullen ${ }^{3}$ \\ ${ }^{1}$ Department of Ophthalmology, Ospital ng Makati; ${ }^{2}$ Department of \\ Ophthalmology, Cardinal Santos Medical Center; ${ }^{3}$ Singapore National Eye Center
}

\begin{abstract}
Aim or Purpose: This study aims to evaluate and compare the proximal, medial, and distal segments of internal carotid artery (ICA) peak systolic velocities (PSV) in patients with non-arteritic anterior ischemic optic neuropathy (NA-AION) in one eye against the contralateral side with normal eye findings using Doppler ultrasound.

Methods: This is a single-center, cross-sectional study of five patients with unilateral NA-AION. The peak systolic velocity (PSV) of the proximal, medial, and distal segments of the ICAs on both sides, one side with NA-AION while the contralateral side had normal eye findings, were compared and analyzed.

Results: Four females and one male with a mean age of 59 years (SD $=17$ years) were included. PSV of the ICA was measured in three segments: Proximal (PICA), Medial (MICA), and Distal (DICA). Mean PSV of eyes with NA-AION was $143 \mathrm{~cm} / \mathrm{sec}(S D=177 \mathrm{~cm} / \mathrm{sec}), 159$ $\mathrm{cm} / \mathrm{sec}(S D=189 \mathrm{~cm} / \mathrm{sec}), 98 \mathrm{~cm} / \mathrm{sec}(S D=34 \mathrm{~cm} / \mathrm{sec})$ for PICA, MICA and DICA respectively. Mean PSV of contralateral side without NA-AION was $95 \mathrm{~cm} / \mathrm{sec}(S D=72 \mathrm{~cm} / \mathrm{sec}$ ), $101 \mathrm{~cm} / \mathrm{sec}(S D=53 \mathrm{~cm} / \mathrm{sec}), 140 \mathrm{~cm} / \mathrm{sec}(S D=60 \mathrm{~cm} / \mathrm{sec}$ ) for PICA, MICA and DICA respectively. There was no statistically significant difference between the two groups along the three segments ( $T$-test PICAp $=0.369$, MICAp $=0.402$, DICAp $=0.112$ ).

Conclusion: Mean PSV was higher in eyes with NA-AION at the proximal and medial segments of the ICA, while it was lower at the distal segments compared to the contralateral non-NA-AION side.
\end{abstract}

Keywords: NA-AION, carotid ultrasound, internal carotid artery, peak flow velocity The authors have no financial interest in this study.

\section{Introduction}

Anterior ischemic optic neuropathy (AION) is the most common acute optic neuropathy in middle-aged patients, reflecting ischemic damage to the optic nerve head. ${ }^{1}$ AION is classified as either arteritic or non-arteritic. The non-arteritic form (NA-AION) is more common and occurs at a mean age of sixty years.

$A$ region-wide census in the Philippines has been reported on the etiologies of optic neuropathies and showed that ischemia is one of the most common cause (50 cases out of 350). ${ }^{2}$ In addition, a neuro-ophthalmology census done in Makati City ${ }^{3}$ also reported that ischemic optic neuropathy is one of the most common diseases seen in the neuro-ophthalmology clinic and NA-AION accounts for seven out of 28 cases of optic neuropathies for the year 2011. Clinically, patients with NA-AION are

Correspondence: Karen B. Reyes

E-mail:kurr b reyes@yahoo.com 
described to have sudden, painless, loss of vision in one or rarely in both eyes with a hyperemic swollen disc at outset.

The etiology of NA-AION is now accepted as perfusion defect in the optic nerve head blood supply which is via the posterior ciliary arteries which are branches of the internal carotid artery (ICA). An evaluation of the ICA may be helpful in our further understanding of NA-AION. Carotid Doppler Imaging is one of the most common and non-invasive method used to assess the carotid artery, ${ }^{4,5}$ particularly in patients suspected to have stenosis where peak systolic velocities (PSV) of the ICA are elevated. ${ }^{6}$ Published reports showed a link between stenosis and other ophthalmic disorders such as glaucoma and ocular ischemic syndromes but studies on the relation between NA-AION and carotid artery stenosis have been limited as to date.-9 Due to the scarcity of knowledge on the exact mechanism of NA-AION, further studies on the blood supply of the optic nerve head may contribute additional information on this condition.

The purpose of this study is to evaluate and compare the proximal, medial, and distal segments of the cervical internal carotid artery (ICA) peak systolic velocities (PSV) in patients with NA-AION in one eye against the contralateral side with normal eye findings using Doppler ultrasound.

\section{Patients and methods}

This is a single-center cross-sectional study of five patients with unilateral NA-AION at Ospital Ng Makati performed over the course of six months. The peak systolic velocities (PSV) of the proximal, medial, and distal segments of the ICAs on both sides, one side with NA-AION while the contralateral side had normal findings, were compared and analyzed.

Ethics approval was obtained from the local ethics review board. Informed consent was obtained from all subjects. The study was done in accordance with the World Medical Association's Declaration of Helsinki.

Included in the study were consecutive patients clinically diagnosed with NA-AION in one eye by the in-house neuro-ophthalmologist. For this study, NA-AION was diagnosed with the following clinical presentation: patients aged 40 years and above with ischemic risk factors (systemic hypertension, diabetes mellitus, hyperlipidemia) presenting with acute painless loss of vision, dyschromatopsia, a positive relative afferent papillary defect (RAPD) and hyperemic disc edema on the affected eye with a contralateral 'disk at risk' characteristics and visual fields defects on the affected eye showing an altitudinal or nasal defect. ${ }^{10-12}$

Exclusion criteria were patients who had bilateral NA-AION, and those who did not follow the typical clinical presentation of NA-AION such as patients younger than 40 years old, and those with chronic or gradually progressive visual loss. Also excluded were patients with underlying systemic disorders that can cause compressive, toxic, or nutritional optic neuropathies. 


\section{Clinical evaluation}

All patients underwent a complete clinical history and neuro-ophthalmologic examination namely: best-corrected visual acuity (BCVA), Ishihara color plates, confrontation visual fields, red-dot perimetry test, ocular motility test, Goldmann applanation tonometry, gonioscopy, anterior and posterior segment examination, cranial nerve examination and automated visual fields examination.

Once a diagnosis of unilateral NA-AION was established, the affected eye with its ipsilateral ICA was labelled as the NA-AION side while the contralateral ICA labelled as the non-NA-AION side.

All patients were fully informed of the nature and details of the procedure, including the benefits and risks involved.

\section{Carotid Doppler Ultrasound Technique}

Carotid Doppler was performed using the the Acuson $\mathrm{X} 30^{\circledR}$ (Siemens, Erlangen, Germany). Patients were placed on a supine position with the head turned contralateral to the side to be examined. Acoustic coupling gel was applied over the neck and the scan in grayscale B-mode started from the proximal common carotid artery and moved distally. After identifying the carotid artery, color flow information was superimposed on the gray scale image to identify flow within the artery and potential areas of high velocity. Blood going towards the probe was designated as color red and blood going away the probe as color blue. Peak systolic velocities of the proximal ICA (PICA), medial ICA (MICA), distal ICA (DICA) and the presence or absence of plaque and/or turbulence were obtained. The same procedure was repeated on the opposite carotid artery. A hard copy of the examination was taken.

\section{Data analysis}

Statistical analysis was performed using the IBM ${ }^{\circledR}$ SPSS $^{\circledR}$ Statistics Version 20. Mean and standard deviations were calculated. Paired student T-test was used to compare means with the level of significance set at $\mathrm{P}<0.05$.

\section{Results}

Five patients were included in the study: four females and one male, with a mean age of 59.6 years ( $S D \pm 17.3$ years). All patients had at least one poorly-controlled ischemic risk factor at the time of NA-ION diagnosis (Table 1). All patients underwent Carotid Doppler examination within two weeks after initial diagnosis. 
Table 1. Baseline characteristics of patients included in the study.

\begin{tabular}{|c|c|c|c|c|c|c|c|}
\hline Patient & Age & Sex & $\begin{array}{c}\text { Onset of } \\
\text { symptoms } \\
\text { prior to } \\
\text { NA-ION } \\
\text { diagnosis } \\
\text { (weeks) }\end{array}$ & $\begin{array}{l}\text { Blood } \\
\text { Pressure } \\
\text { (mmHg) }\end{array}$ & $\begin{array}{c}\text { FBS* } \\
(\mathrm{mmol} / \mathrm{L})\end{array}$ & $\begin{array}{c}\text { Total } \\
\text { Cholesterol } \\
\text { (mmol/L) }\end{array}$ & Medications \\
\hline 1 & 50 & $\mathrm{~F}$ & 4 & $130 / 80$ & 25.00 & 2.99 & $\begin{array}{c}\text { Losartan } 50 \mathrm{mg}+\text { hydro- } \\
\text { chlorothiazide } 12.5 \mathrm{mg} / \\
\text { tab OD } \\
\text { Aspirin } 80 \mathrm{mg} / \mathrm{tab} \\
\text { Clopidogrel } 75 \mathrm{mg} \text { tab, OD } \\
\text { Glipizide } 5 \mathrm{mg} \text { tab OD } \\
\text { Metformin } 500 \mathrm{mg} / \mathrm{tab} \mathrm{BID} \\
\text { Atorvastatin } 40 \mathrm{mg} \text { tab OD }\end{array}$ \\
\hline 2 & 50 & $\mathrm{~F}$ & 1 & $120 / 80$ & 9.00 & 5.50 & $\begin{array}{l}\text { No maintenance } \\
\text { medication }\end{array}$ \\
\hline 3 & 74 & $\mathrm{~F}$ & 3 & $130 / 80$ & 5.10 & 7.47 & $\begin{array}{c}\text { Rosuvastatin } 20 \mathrm{mg} / \mathrm{tab} \\
\mathrm{OD}\end{array}$ \\
\hline 4 & 42 & $\mathrm{~F}$ & 2 & $130 / 80$ & 5.00 & 5.52 & $\begin{array}{c}\text { Losartan } 50 \mathrm{mg}+\text { hydro- } \\
\text { chlorothiazide } 12.5 \mathrm{mg} / \\
\text { tab BID } \\
\text { Aspirin } 80 \mathrm{mg} / \mathrm{tab} \text { OD }\end{array}$ \\
\hline 5 & 82 & M & 4 & $120 / 80$ & 8.40 & 5.53 & $\begin{array}{c}\text { Enalapril } 5 \mathrm{mg} / \mathrm{tab} \text { OD } \\
\text { Amlodipine } 10 \mathrm{mg} / \mathrm{tab} \text { OD } \\
\text { Aspirin } 80 \mathrm{mg} / \mathrm{tab} \text { OD } \\
\text { Atorvastatin } 40 \mathrm{mg} / \mathrm{tab} \\
\text { OD }\end{array}$ \\
\hline
\end{tabular}

Laboratory Values Normal Range: Fasting Blood Sugar*: 4.11-5.49 mmol/L; Cholesterol: 0.00-5.20 mmol/L

\section{Presence/absence of turbulence and plaques}

All ICAs evaluated from both sides did not show any turbulence or plaques.

\section{Proximal internal carotid peak flow velocity}

Mean PSV of the PICA on the NA-AION side was $143 \mathrm{~cm} / \mathrm{sec}$ with a standard deviation (SD) of $177 \mathrm{~cm} / \mathrm{sec}$, while the mean PSV of the PICA on the non-NA-AION side was $95 \mathrm{~cm} / \mathrm{sec}$ with a SD of $72 \mathrm{~cm} / \mathrm{sec}$. The mean PSV was higher on the NA-AION side, but was not statistically significant $(P=0.369$, Table 2$)$.

\section{Medial internal carotid peak flow velocity}

Mean PSV of the MICA on the NA-AION side was $159 \mathrm{~cm} / \mathrm{sec}$ with a standard deviation (SD) of $189 \mathrm{~cm} / \mathrm{sec}$ while the mean PSV of the MICA on the non-NA-AION side was $101 \mathrm{~cm} / \mathrm{sec}$ with a SD of $53 \mathrm{~cm} / \mathrm{sec}$. The mean PSV of the MICA was also higher on the NA-AION side, but was also not statistically significant $(P=0.402$, Table 2$)$. 


\section{Distal internal carotid peak flow velocity}

Mean PSV of the DICA on the NA-AION side was $98 \mathrm{~cm} / \mathrm{sec}$ with a standard deviation (SD) of $34 \mathrm{~cm} / \mathrm{sec}$, while the mean PSV of the DICA on the non-NA-AION side was $140 \mathrm{~cm} / \mathrm{sec}$ with a SD of $60 \mathrm{~cm} / \mathrm{sec}$. The mean PSV of the DICA was lower on the NA-AION side, but was not statistically significant $(P=0.112$, Table 2$)$.

Table 2. Comparison of Internal carotid artery peak systolic velocity of unilateral NA-AION.

\begin{tabular}{|l|l|l|l|}
\hline \multirow{2}{*}{ Proximal ICA } & & Mean PSV & p-value \\
\hline \multirow{2}{*}{ Medial ICA } & NA-AION side & $143 \mathrm{~cm} / \mathrm{sec}$ & \multirow{2}{*}{0.369} \\
\cline { 2 - 3 } & Non-NA-AION side & $95 \mathrm{~cm} / \mathrm{sec}$ & \\
\hline \multirow{2}{*}{ Distal ICA } & NA-AION side & $159 \mathrm{~cm} / \mathrm{sec}$ & \multirow{2}{*}{0.402} \\
\cline { 2 - 3 } & Non-NA-AION side & $101 \mathrm{~cm} / \mathrm{sec}$ & \\
\cline { 2 - 3 } & NA-AION side & $98 \mathrm{~cm} / \mathrm{sec}$ & \multirow{2}{*}{0.112} \\
\cline { 2 - 3 } & Non-NA-AION side & $140 \mathrm{~cm} / \mathrm{sec}$ & \\
\hline
\end{tabular}

$P<0.05=$ level of significance, two-tailed

\section{Discussion}

In the few studies concerning the relationship between the ICA and ischemic optic neuropathy, all stated that there was no association between carotid stenosis and the said condition..$^{13-15}$ The results were similar in our study, although PICA and MICA PSVs were higher $(143 \mathrm{~cm} / \mathrm{sec}$ and $159 \mathrm{~cm} / \mathrm{sec}$ respectively) on the NA-AION side, but no turbulence was seen, thus the criteria for stenosis were not fulfilled.

A study evaluating peak flow velocity (PFV) of the ophthalmic artery using transcranial Doppler showed a decreased PFV on the NA-AION side. ${ }^{7}$ In another study comparing blood flow velocities of the ophthalmic artery, central retinal artery and posterior ciliary arteries of patients with NA-AION against age-matched controls showed a decreased velocity in the central retinal artery and the nasal posterior ciliary artery in patients with NA-AION. ${ }^{16}$

Assessing the ICA along the neck is easier and more accessible compared to performing a transcranial Doppler. In our study, we found a higher PSV in the proximal and medial ICA of the NA-AION patients but not in their distal ICA. The PSV of the DICA in the NA-AION group was found to be lower. This finding coincides with the abovementioned studies, ${ }^{7,16}$ where the PSV of the ophthalmic artery, the central retinal artery and posterior ciliary artery ${ }^{19}$ of eyes with NA-AION were lower. The results from our study and from others, although similar, are not statistically significant.

The findings of our research contradict Bernoulli's equation which states that flow velocities increase as a result of constriction or narrowing of a vessel lumen.,, 17 And a failure in autoregulation may also explain why flow velocities are lower in eyes with NA-AION. Furthermore a malfunction in the autoregulatory process has 
been reported to occur in vaso-occlusive diseases bringing about compensatory blood flow from other vessels thereby lowering the flow velocity. ${ }^{7,18-19}$

In conclusion, our study has demonstrated that the mean PSV is higher in eyes with NA-AION at the proximal and medial segments of the ICA, while it is lower at the distal segments compared to that on the contralateral non-NA-AION side.

\section{References}

1. Arnold AC. Ischemic optic neuropathy. In: Miller NR, Newman NJ, Biousse V, Kerrison JB (eds.), Walsh and Hoyt's Clinical Neuro-Ophthalmology. $6^{\text {th }}$ ed., Vol. I, pp. 349-384. Philadelphia: Lippincott Williams \& Wilkins 2005.

2. Garganta RG, Tamesis JM, Ang LT. Common Etiologies of Optic Neuropathies among Filipinos seen in Metro Manila, Philippines: A One-year Retrospective Study. J Neuroophthalmol 2012;36(Suppl 1):12.

3. Reyes KB, Dimayuga WA. Incidence of neuro-ophthalmic cases in Makati City, Philippines NeuroOphthalmology. J Neuroophthalmol 2012;36(Suppl 1):18.

4. Society of Radiologists in Ultrasound. Carotid Artery Stenosis: Gray-Scale and Doppler US Diagnosis - Society of Radiologists in Ultrasound Consensus Conference. Radiology 2003;229:340-346.

5. Gerhard-Herman M, Beckman JA, Creager MA. Vascular laboratory tessing. In: Creager MA, Beckman JA, Loscalzo J (eds.), Vascular Medicine A companion to Braunwald's Heart Disease, $2^{\text {nd }}$ ed., pp. 148-155. Philadelphia: Saunders 2013.

6. Gonzales-Tanque M (compiled by). Philippine Society of Vascular Medicine - Philippine Heart Association. Vascular Ultrasound Concensus Workshop 2011.

7. Sanjari MS, Falavarjani KG, Mehrabani M, Ghiasian L, Zamani B. Retrobulbar hemodynamics and carotid wall thickness in patients with non-arteritic anterior ischemic optic neuropathy. $\mathrm{Br} J$ Ophthalmol 2009;93(5):638-640.

8. Lyons Wait VA, Anderson SF, Townsend JC, et al. Ocular and systemic findings and their correlation with hemodynamically significant carotid artery stenosis: a retrospective study. Optom Vis Sci 2002;79:353-362.

9. Barkana $Y$, Harris $A$, Hefez $L$, et al. Unrecordable pulsatile ocular blood flow may signify severe stenosis of the ipsilateral internal carotid artery. Br J Ophthalmol 2003;87:1478-1480.

10. Kerr NM, Chew SS, Danesh-Meyer HV. Non-arteritic anterior ischaemic optic neuropathy: a review and update. J Clin Neurosci 2009;16(8):994-1000.

11. Hayreh SS, Zmerman B. Visual field abnormalities in nonarteritic anterior ischemic optic neuropathy: their pattern and prevalence at initial examination. Arch Ophthalmol 2005;123:1554-1562.

12. Chua D, Cullen JF. Incipient non-arteritic anterior ischemic optic neuropathy: a distinct clinical entity, the Singapore scene 3. Singapore Med J 2014;55(9):473-475.

13. Arnold AC. Pathogenesis of Nonarteritic Anterior Ischemic Optic Neuropathy. J Neuroophthalmol 2003;23:157-163.

14. Fry CL, Carter JE, Kanter MC, Tegeler CH, Tuley MR. Anterior ischemic optic neuropathy is not associated with carotid artery atherosclerosis. Stroke 1993;24:539-542.

15. Muller M, Kessler C, Wessel K, et al. Low-tension glaucoma: a comparative study with retinal ischemic syndromes and anterior ischemic optic neuropathy. Ophthalmic Surg 1993;24:835-838.

16. Kaup M, Plange N, Arend KO, et al. Retrobulbar hemodynamics in nonarteritic anterior ischemic optic neuropathy. Br J Ophthalmol 2006;90:1350-1353.

17. Kagemann L, Harris A, Chung HS, et al. Basics and limitations of CDI. In: Pillunat LE, Harris A, Anderson DR, et al. (eds.), Current concepts on ocular blood flow in glaucoma, pp. 103-110. The Hague: Kugler Publications 1999.

18. Muller M, Schimrigk K. Vasomotor reactivity and pattern of collateral blood flow in severe occlusive carotid artery disease. Stroke 1996;27:296-299.

19. Costa VP, Kuzniec S, Molnar LJ, et al. Collateral blood supply through the ophthalmic artery: a steal phenomenon analyzed by color Doppler imaging. Ophthalmology 1998;105:689-693. 